\title{
Conventions and Commitments in Distributed CSCW Groups
}

\author{
GLORIA MARK \\ Department of Information and Computer Science, University of California, Irvine, CA 92697, USA \\ (E-mail: gmark@ics.uci.edu)
}

\begin{abstract}
Conventions are necessary to establish in any recurrent cooperative arrangement. In electronic work, they are important so as to regulate the use of shared objects. Based on empirical results from a long-term study of a group cooperating in electronic work, I present examples showing that the group failed to develop normative convention behavior. These difficulties in forming conventions can be attributed to a long list of factors: the lack of clear precedents, different perspectives among group members, a flexible cooperation media, limited communication, the design process, and discontinuous cooperation. Further, I argue that commitments to the conventions were difficult, due to the conventions not reaching an acceptance threshold, uneven payoffs, and weak social influences. The empirical results call for a specific set of awareness information requirements to promote active learning about the group activity in order to support the articulation of conventions. The requirements focus on the role of feedback as a powerful mechanism for shaping and learning about group behavior.
\end{abstract}

Key words: articulation, awareness, conventions, empirical studies, groupware, shared workspace

\section{The role and purpose of conventions in cooperation}

\subsection{INTRODUCTION}

Conventions are essential for governing cooperation. Yet the suitable support for conventions in cooperative system design is an area that has received remarkably too little attention so far. This paper addresses an important requirement for successful cooperation in electronic work: namely, the establishment and maintenance of appropriate conventions when a group is distributed.

Establishing conventions is a means for a group to effectively manage interaction in electronic work. A team that has a long history of shared experience may have already established conventions for many of its cooperative activities, yet people who are brought together to cooperate through a groupware system must begin anew in forming conventions. Such agreed-upon rules of interaction increase the chances that cooperative work can result in process gain, rather than process loss, as for example if one member should restructure or rename files, resulting in an extra effort for other cooperating partners to find the documents. One user's action on a shared document, such as changing text or even access rights, affects all users working on the shared document. Especially in asynchronous distributed 
work, conventions are important in that they enable people to keep track of, and predict processes, for example, stages of document completion. Also importantly, conventions are a means for new members to smoothly adapt to electronic work, such as when a group's membership is dynamic.

\subsection{A CONVENTION EXAMPLE}

Compared to the use of conventions in physically collocated work, conventions in a distributed group are difficult to identify, to specify, and to maintain. In this paper I present a case study to illustrate these difficulties. However, I first describe an example of convention use that is successful across distance. This example shows that a successful convention can enable a group to achieve a lot.

During World War I, a unique form of cooperation between the opposing sides emerged. For those soldiers involved in trench warfare, the different sides were separated by a few hundred yards on the border of France and Belgium. While the divide was too distant for the different parties to speak to and hear each other, they could see each other, and a policy of mutual restraint was enacted (Ashworth, 1980). The longer the interaction, the more stable was the cooperation, i.e. both sides used the strategy of avoiding to shoot. This cooperative spirit endured for the most part even though the high commands on both sides promoted an offensive strategy. In those cases when the high command enforced orders for large battles, they were carried out, but for the time in between, the cooperation was resumed. Outgoing units would explain the implicit cooperative arrangement to incoming units. The cooperation patterns even extended to the point that both sides shot at predictable targets and times, to satisfy the high command, but also to fulfill the cooperative arrangement. Although this "live-and-let live" system eventually disintegrated due to a new policy of continual raids, the sustained cooperation demonstrates a convention of mutual reciprocity that developed in the two groups, even though they were distant.

The use of the convention between the two groups of trench soldiers illustrates its role in governing cooperation. Cooperation is constituted by mutual interdependencies (Schmidt and Bannon, 1992; Malone and Crowston, 1994). In the example of the trench soldiers, the two groups became highly interdependent in their goal of survival: they were both at the mercy of the high command to follow orders and were monitored. The soldiers understood the similarities of their situation; they all knew that they were in an interdependent prisoners' dilemma, and they collectively developed and followed a course of action to achieve a clear mutual goal of remaining alive.

Thus, the trench soldiers developed a form of cooperation regulated by a convention of refraining from harming the other side. While this example provides a clear illustration of how critical a convention might be for a group (in this case, to survive), conventions can achieve a number of different ends in cooperation. Conventions are important in group interaction in that they reduce the trial and error 
and confusion by regulating mutually interdependent activities so that they do not interfere with each other. The conventions thus provide a modus vivendi for making interactions proceed smoothly (Feldman, 1984; Conte and Castelfranchi, 1995). In general, conventions can regulate many types of group interactions, ranging from communication (Lenke et al., 1995), interpersonal distance (Hall, 1966), the use of artifacts, and even the control of negative social processes such as cheating.

\subsection{CONVENTIONS FOR ELECTRONIC WORK}

I define conventions for electronic work to be agreements among group members on methods for local control of a computer system for performing work. I use the term local to distinguish from global coordination plans that the group may have for conducting work, such as project schedules, roles, deliverables, plans for background research, and so on. The global plan may represent the general path for the group, but the means to achieve these ends with a groupware system involves setting local procedures. These local procedures might include who has access rights for which documents, how shared information should be structured, when distribution lists should be used, perhaps even when to read email. The conventions in this sense establish the "social infrastructure" for how the group will use the groupware system to conduct their work. Members of a work team, when working together for the first time using a new groupware system, may understand the project plan, schedule, and roles, but they also need to set agreements for feasible local interactions when using the system. In other words, users cannot simply be given a groupware system and be expected to optimally use it without some common agreements on the means of operation.

The purpose of conventions can be distinguished from the purpose of coordination mechanisms in CSCW (Schmidt and Simone, 1996). Such mechanisms are designed to regulate coordination through a protocol, which designate procedures surrounding a particular artifact. Examples of coordination mechanisms in cooperative work include flight strips in air traffic control (Harper and Hughes, 1993), a whiteboard used to check out common files (Rogers, 1993), classification schemes (Star and Griesemer, 1989), and cards showing state of affairs and production orders, known as the kanban system (Schmidt and Simone, 1996). To fulfill its mediating function for actors' interdependencies, a coordination mechanism is distinct from the field of work, whereas conventions can be formed concerning shared objects used in the field of work. Conventions are intended thus to solve a particular case of coordination. There can of course be conventions surrounding the use of a coordination mechanism, which Schmidt and Simone refer to as coordinative protocols, but in this paper, I focus on conventions that are formed to regulate the usage of shared objects transacted in the field of work.

In a distributed group, the accommodation process whereby individuals learn about each other and develop group procedures is severely compromised. I refer to a distributed group as one whose members' main work activity is not in close 
proximity to each other, so that the members' main channel of communication is not face-to-face, but is rather telephone, email, chat, or other computer-mediated media. Such communication channels are not as rich as face-to-face in communicating social and nonverbal actions, and in comparison, all constrain communication to different degrees. Feedback plays an essential role in this accommodation process, to reinforce appropriate behaviors in the group and to direct people away from inappropriate actions. Violating conventions may not be so obvious as when group members are face-to-face. Also, feedback sanctions on violations may be weaker.

In the next section, I describe a case study which illustrates the difficulty for a distributed group in recognizing coordination situations and enforcing conventions. Along with the difficulties, a theory of convention use is presented. In section 3 , the reasons for the difficulties that the group had in forming and committing to conventions are discussed. In section 4, the role of awareness information in helping a distributed group form and maintain conventions is explained.

\section{A case study: Conventions for electronic work}

The study took place in Germany, where historical and political circumstances motivated the development of a prototype groupware system to support distance cooperation. Bonn served as the capital of West Germany from 1949 until German reunification in 1990, and in 1991, the parliament chose Berlin as the new capital. The relocation of the government has been a lengthy and costly process. Federal agencies will relocate over time, resulting in a large division of labor in departments spread between the old and new capitals. The POLIKOM research program instituted by the Federal Ministry of Education, Science, Research and Technology, established as its goal the development of telecooperation systems to support the cooperation between the distributed governmental functions in Bonn and Berlin (Hoschka et al., 1993). Within this program, the PoliTeam groupware system was specifically designed to build a "telecooperation bridge" between Bonn and the new German capital of Berlin. The main function of the PoliTeam system is to supplement paper work processes with electronic work processes in a government ministry. To accomplish this, PoliTeam offers a shared workspace and electronic circulation folders (Prinz and Kolvenbach, 1996). An already existing groupware system (LinkWorks) was chosen and adapted to specific user and situation requirements. For further information, see Klöckner et al. (1995).

The implementation strategy was to set up prototypes in three representative areas of the government, to enable an investigation of how users were adapting to the system, and to correct mistakes early. These prototypes were set up in the Federal Ministry of Family Affairs, Senior Citizens, Women, and Youth, located in Bonn, the State Representative body of Mecklenburg, located in Western Pomerania, and the Ministry of Justice, in Schwerin, in northern Germany. Further, an evolutionary cycling approach was used in the design, allowing modifications to 
be made over time and which designers and users reported as beneficial (Mambrey et al., 1998). The project began in May 1994, and after almost one year of preparation, the system was first installed in January, 1995. Following this, new versions have been installed roughly about every year for the next three years, in February, 1996, December, 1996, and the final version in December, 1997. The official end of the research project was in April, 1998, as originally planned.

\subsection{RESEARCH SETTING AND METHODS}

The focus of the study reported in this paper at the time of writing was at the Federal Ministry which currently has 12 primary users, in Bonn: one unit leader, six ministry employees (responsible for specific content areas of the ministry), three typists in their own service unit, and additionally in Berlin: two users. The Bonn employees collaborate using the shared workspace and email.

The results used to describe the case study are from a collection of material: workshops, site visits, design-team-user discussions, and user interviews. Initial semi-structured interviews were conducted before the system was introduced in order to learn about the potential users' work practice. Transcripts were also used from workshops, in which the design team met with users: shortly after the first system version was finished, and about every six months thereafter. A long list of user requirements for conventions emerged during a workshop held in July, 1996.

Twice after system introduction, a series of semi-structured interviews with the users was conducted. In the first set of interviews, which lasted one to three hours each, users were asked about: training and support, individual and collective work with the system, cooperation and use of information, the search facility, awareness of others, the shared workspace, and conventions: how the users had established some conventions, disturbing actions from others, conventions needed, violations, views on conventions, and their effect on work styles. A second set of interviews was conducted shortly before the project ended, in order to develop an overview of costs and benefits of system use. Information was also used from a log of reported problems and results from the user hotline and weekly site visits of design team members.

\subsubsection{The heterogeneous cooperating groups}

The shared workspace in PoliTeam is used in a cooperative arrangement by two different groups in the Ministry: typists in a central writing office, and members of a Ministry unit. The two groups can be distinguished by differences in jobs, tasks, education levels, career path orientations, salaries, computer experience, and even more. The two groups are also spatially distributed, located on different floors of the same building in the Ministry.

The Ministry unit consists of nine members. Their job is to support the Minister that they work for through activities such as speech-writing, information dissemination, and answering citizens' queries. At the time of the PoliTeam system 
introduction, most unit members were inexperienced in using computers; many in fact had never used a computer before.

Members in the writing office who use PoliTeam are a coordinator and three typists who type electronic versions of documents for the Ministry unit members. Before PoliTeam, the typists had used word processors, and thus were quite familiar with text processing systems. Before PoliTeam was introduced, the typists typed all work for the Ministry. Typing was done from handwritten texts or voice recordings. Transport of the information was done by an internal courier who made two pickups/deliveries per day: in the morning and afternoon. After the system introduction, the ministry unit members began to make small changes in the documents themselves, and even began to type more documents themselves.

After PoliTeam was introduced, the exchange of documents was done through the shared workspace. The shared workspace has two purposes. First, it provides shared document access for the writing office and the Ministry unit, thus enabling intergroup cooperation. The writing office places a document into a unit member's workspace when the typing is finished. The workspace also provides access to a unit member text for the production of a finished copy. Second, it provides shared access to people within the Ministry unit enabling intragroup cooperation. It enables unit members to exchange documents among themselves, such as when they coauthor documents. It also provides access for the unit leader to all documents that have been produced within the unit. And finally, it provides access to common information sources about the Ministry, which all users update.

\subsubsection{The organizational influence: The GGO}

Ironically, what is written as strict rules of organizational procedure in the Ministry seems to have little effect on the users' electronic work practice. Work is organized accorded to the Common Rules of Procedure of the Federal Ministries, abbreviated in German as the GGO. The GGO specifies how work has to be organized: only official documents exist. This is because the only work allowed is official work, done on behalf of, and by roles that substitute for, the Minister in person. All work must be documented and should be exchanged according to a detailed work flow process. In actual work practice, the hierarchical, strictly formal bureaucracy is intertwined with officially "invisible" informal work. Despite this idea of official and public work within the organization, the employees have their own private work, such as preparing early drafts of a speech. These are not publicly available.

In the requirements analysis, the users requested to have a personal workspace in the system to store their private documents, which goes against the formal GGO. The users reported that they became very careful as to which documents they put in the shared folder, knowing that all would have access to it. Thus, although a formal set of rules exist in the Ministry to prescribe and define how work should proceed, the users have neglected to follow these prescriptions in their use of the shared workspace. 


\subsection{THE DIFFICULTY IN FORMING CONVENTIONS}

The conventions needed for a groupware system like PoliTeam are vast. The following are examples of conventions that were found to be difficult for the users to establish, and that were typical of their work with the system:

- Storing old and current documents: There was no clear convention for developing a common information structure, nor a convention for archiving information, e.g. defining "old" and "new" documents. Twelve users collect a huge volume of information. They had been storing documents in one file cabinet which the users claim has become too huge to manage.

- Conventions regarding shared tasks: what changes to accept in a document; who should make the changes; a model for access rights for different classes of documents; and different "closets" (based on an office metaphor, used in PoliTeam); when should a document be produced and sent as an alias, or copy; editing text; who should be the owner of a document; production of new documents (e.g. where should it be produced, where should an alias be stored, where should ongoing and finished documents be stored).

- Conventions for determining places for storage: which documents should be stored publicly, and which privately?

- Substitution rules for when a workspace member is absent. The users raised concerns that they needed conventions for accessing personal documents of others. A personal workspace made available to a substitute might be confusing, since the information structure is highly personal.

- Conceptual vs. physical owner of a document. Traditionally, when one dictates a document onto a cassette, or writes a draft on paper, or creates a document on a single-user system, then one is the "owner" of the document. However, when multiple users in a shared workspace work on a document, "ownership" becomes vague. This becomes an issue when one person is the coordinator of the document, yet another person has created the document and fails to change access rights.

- Conventions regarding the electronic circulation folder, including how and when notification should occur.

- Other more basic conventions, including conventions for using email, and general system use.

Conventions were especially difficult to identify for new work processes that emerged in the course of using the groupware. For example, a shared folder opportunistically set up between ministry departments in Bonn and Berlin enabled documents to be accessed almost immediately, whereas before PoliTeam, they were exchanged via regular mail. However, this new ability to transact information fast, and to make it accessible, posed a new kind of question to the users. They needed to determine conventions for the shared workspace between Bonn and Berlin: on organization, on types of information, and access. As one Unit member reported: 
When we use more information together with Berlin, then we must really think what [shared work areas] would be useful. For example, should we have things where we pack five things inside, or something else? It also depends on what it is, what kind of information. I think that in certain folders, it must be this way. It is necessary. Otherwise we have chaos. Or someone has chaos for themselves.

Most users reported that they do not have a clear idea of the activities of other users. The Bonn-Berlin users had met each other only infrequently. But it was not only the unfamiliarity of each others' work practices, but also a lack of awareness of others' use of shared objects that was reported as an obstacle in defining conventions:

We must think over, depending on the information that we have, which shared work areas would be sufficient. But I'm not in the situation where I can see that, i.e. where I get information other than that for my own workspace.

For my own archive, what I set up myself, then I can look at my own example. But for a real [shared] archive, that would be set up for others, then we must really think it over; what the system offers, and what is necessary. But I can't evaluate that at this point.

\subsubsection{Conventions: A normative view}

The above examples illustrate that a wide range of conventions were needed for using the groupware system, yet they were difficult for the group to define. The user experiences show that there can be a wide gap between normative cooperative behavior in physically collocated work, and actual cooperative behavior in distributed electronic work. In order to examine this discrepancy further, I present a definition of normative convention behavior in physically collocated work, according to Lewis (1969):

A regularity $\mathrm{R}$ in the behavior of members of a population $\mathrm{P}$ when they are agents in a recurrent situation $S$ is a convention if and only if it is true that, and it is common knowledge in $\mathrm{P}$ that, in any instance of $\mathrm{S}$ among members of $\mathrm{P}$,

- everyone conforms to R;

- everyone expects everyone else to conform to R;

- everyone prefers to conform to $\mathrm{R}$ on condition that the others do, since $\mathrm{S}$ is a coordination problem and uniform conformity to $\mathrm{R}$ is a coordination equilibrium in $\mathrm{S}$.

Although in its strictest form Lewis' definition requires that everyone conform to the convention, he proposes a relaxed alternative where "almost everyone" in the group conforms, expects to conform, and prefers conformity to R. But even in the case where most conform, this definition presents a prescriptive model of convention behavior in a group.

Following this normative model, as a consequence of beginning to conform to the convention, group members develop expectations that others in the group will conform. This leads to commitments which sustain the convention. In other words, every new instance of conforming to the convention increases the group's 
experience that when the situation arises, people will use the convention. This set of experiences leads to the expectation that other group members will continue to follow the convention in the future. And the expectation that others will conform in the future is reason to continue to conform: if I conform, then others will. This leads to a number of higher-order expectations that are instrumental in sustaining the use of conventions.

The convention represents mutual knowledge and expectations in the group. The existence of a convention implies that all in the group have common knowledge that this convention leads to solving a coordination problem. Moreover, according to this normative view, to belong to the group might imply that each member possesses the common knowledge associated with the group convention. Conventions thus contribute to the cumulative wealth of common knowledge, experience, and behaviors in the group. The distinguishing characteristic then, of conventions, is that they are emergent properties of the group, rather than of individual members (Turner and Oakes, 1989).

\subsection{THE EMERGENCE OF PROBLEMS WITH INTERDEPENDENCIES}

It requires time for a group to develop conventions in a distributed setting. Information about the development of conventions among the PoliTeam users was derived from logbook data during site visits of user advocates. At their site visits, the user advocates recorded when users had problems in system use and user requirements, along with some general observations. These data were supplemented by user interviews and workshop protocols. The user experiences over time were categorized into three categories using content analysis. Coding was checked by a second coder with $93 \%$ agreement. Where a few discrepancies were found, they were discussed and recategorized.

The categories were:

General System Understanding: Problems that concerned understanding singleuser system functionality, e.g. Word, Excel, icon views, etc.

Individual Use Events: Problems and experiences that concerned system handling of all aspects that do not concern shared objects, e.g. setting up individual document templates, organizing personal directories.

Group Use Events: Problems and experiences that concerned system handling and understanding of shared objects.

The events in General System Understanding were few, and since they concerned single-user functionality, they were combined with Individual Use Events for the description. The six-month divisions seemed to be a reasonable amount of time in which to characterize system use; smaller time categories had less data, and time frames longer than six months lowered the precision. As a result of this categorization, rough phases of group development with the system were identified, and are shown in Figure 1. These phases can be described qualitatively as follows. 
Initially, in the first six months most of the Group Use Events concerned setting up group functionality, by both the typists and Unit leader, e.g. shared folders and new access rights profiles for common document templates. Requirements emerged concerning awareness: the typists wanted the system to automatically notify their clients when documents were completed, and the Unit leader wanted to know who made changes to a shared object. File codes were needed for the common documents. Individual Use Events concerned setting up personal information structures. A lot of "growing pains" were evident.

In the second six months, more group functionality was set up, mostly by the Unit leader: an address list, shared calendar, and internal shared folder. A few groupware requirements emerged: different access rights were needed for different groups, and the date of the shared folder needed to be updated to reflect changes in the contents. Individual Use Events concerned mainly general system understanding. During the third six months, no new functionality had been set up, but it was now being refined, e.g. the document template collection. The users and typists were now established in a group work pattern and were now exchanging a variety of documents quite regularly. Individual Use Events revealed users beginning to customize features of the system, e.g. setting up personal document template collections, and creating email directories. After one and a half years of system use, the Group Use Events were similar to the last phase: functionality was continuing to be refined in minor ways. A few requirements emerged: shared templates for circulation folders, and employee identification in shared document printouts. Individual Use Events continued with minor understanding problems.

After two years of system use, a definite change was evident in the Group Use Events. Many users were now reporting problems as a result of other users' actions: users were concerned that files were taken out of the shared folder and were lying on others' personal desktops, and there was confusion reported in how addresses in the shared address book were organized. First trials of electronic circulation folders were initiated which led to the report of stalled folders (as with paper folders). Individual Use Events were minor.

In the last six months of the project, problems continued to be reported that concerned other users' actions: e.g. deletion of documents. Requirements were that the Berlin users wanted to identify only changes from specific users in Bonn, not all users, to prevent information overload. Also, Berlin and Bonn Unit leaders needed to differentiate their editing with colors. In addition, refinements were made for the awareness feature. Important requirements emerged for establishing a registry for documents. Individual Use Events were still minor.

What is interesting is that the events show that the group is going through a process of struggling to develop conventions. After about two years, now that group functionality has been set up, and work patterns seemingly firmly established, the group members reported problems that concerned coordinating their work patterns. At this point, the group members were beginning to recognize the consequences of their interdependencies. Some evidence shows that the same types of problems 


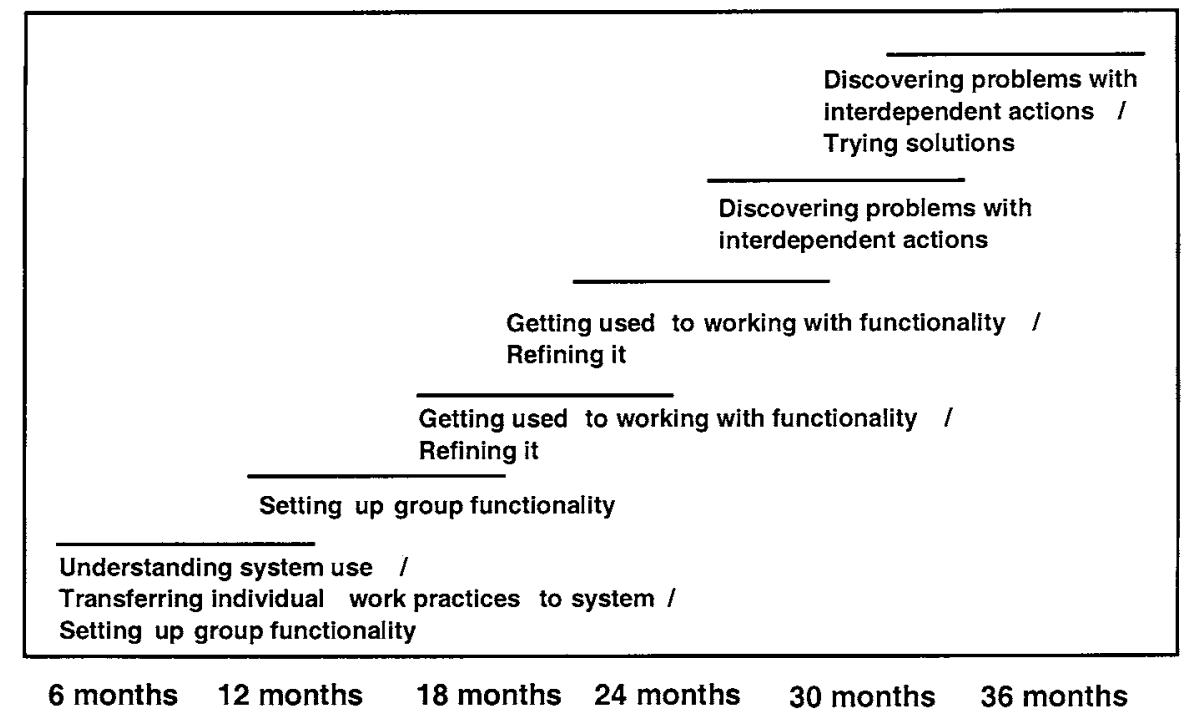

Figure 1. Approximate stages of groupware learning.

with interdependencies occurred very early on in the system use, yet these problems were not considered by users to be due to the actions of other members. For example, in the first three months of system use, the typist complained that an icon which usually turned blue was now turning black due to a system problem. Yet the typist did not make a connection that the color change represented a status change, caused by another user's action. This suggests that only with continued system use, the users gradually became aware of how others' actions were affecting their own system use.

\subsubsection{How a group forms conventions: Feedback and awareness}

It took considerable time for the PoliTeam users to understand the coordination situations for which conventions were needed. Conventions are built upon a foundation of some degree of common ground among actors. Before actors can cooperate, or even communicate, establishing a common ground is essential. Common ground is cumulative, being developed as actors share experiences. It must be reciprocal - each much assume that the other possesses it (Schutz, 1970). Members of the same social group, or people who live and work in proximity, share a considerable degree of common ground (Clark, 1985).

A critical factor for the emergence and functioning of conventions is the information available that communicates social, behavioral, and environmental aspects of the group. This information is the raw material for forming conventions. In physically collocated environments, people are experts at processing information: they detect the finest nuances of behavior and expression in other people. They see how others are handling or changing artifacts, and from the context they can 
infer previous changes made to artifacts (Robinson, 1993). By watching others, they generally can get a clear understanding of the other's subjective expressions, and can use this to correct and fine-tune their responses (Schutz, 1970).

Common information and artifacts available to interacting actors can include: people; physical objects such as documents, keys, or books; communicative signals, such as signs of approval, feedback, gestures, status indicators, and facial expressions; and the state of the environment, such as closed doors, placement of telephones, or noise level. The placement, occurrence, and changes of artifacts are embedded within a context. These affect the knowledge and affective states of group members (Hackman, 1976). This common information affects each member's knowledge and beliefs about the group and the work activity. It can also affect the group's attitude, such as what outcomes are desirable. When artifact use, behavior, and expression are easily communicable in a group, then the group can discover where coordination situations exist. The group can then develop methods for regulating their actions.

However, in distributed settings, this information is not readily available. This limited communication and expression affects the ability of a group to form and maintain conventions. Distributed team members do not share a common physical environment, which provides cues of others' whereabouts and state of work, and so actors do not have common orientations and reference points. Environmental information for physically separated actors is local and distinct from one another. Any (environmental, behavioral, and artifact) information common to the group is mostly constrained to an electronic environment. The reduced communication, as well as varying contexts of actors and stimuli, affect the ability for cooperating actors to understand interaction in the same context (Herrmann and Misch, 1999). Thus, it is difficult for actors to "know" how their collaborating partners are handling electronic artifacts, e.g. storing documents, or naming files. Therefore, it requires time for users to learn about each others' actions, if in fact, this information can be made available.

\subsection{PROBLEMS WITH CONVENTION FORMATION: INCONGRUENT CONVENTIONS FORMED IN SUBGROUPS}

In those cases when conventions were formed by the users, problems were discovered. One problem was that the two heterogeneous subgroups in the PoliTeam group had developed different conventions for organizing and using the same information in the shared workspace:

1) The writing office view: The writing office developed a solution to organize documents: first, according to the units and then, by the members of a unit. Thus, each unit member has a workspace, shared with members of the writing office. All these workspaces are contained in another folder, called the unitfolder, resulting in a two-level hierarchy. Whenever the writing office produces a document, it is placed in the appropriate unit/person workspace. This conven- 
tion for how the shared workspaces are organized is logical for the work process of the writing office: their sorting convention uses the name of the document owner and date of creation. A second convention concerns the naming of documents. The typists prefer to name documents according to date and unit member.

2) The unit members' view: The unit members found that it was easier for them to organize their documents according to their work processes. They collected documents produced by the writing office in task or process-specific folders, where each folder represents a distinct process, rather than a unit member. This resulted in a rather deep multi-level structure for many of the users. Their sorting and naming criteria for documents in the workspace was based on the content of a document, e.g. a speech on a senior citizen initiative. This is in contrast to the typists' conventions of sorting and naming by date and unit member.

Documents can be accessed in several ways: by subject, the creator of the document, and a reference code, associated with predefined subjects in the Ministry. The problem is that different users prefer to store and access documents differently. For typists of the department, accessing a document by the creator (or owner) makes much more sense to them than accessing a document by the subject which has little meaning to them. Their primary task is to type documents for unit members; their system is an efficient means for them to access a document. To the unit leaders, who are speech writers, accessing a document by its subject is efficient for them. The dates of the documents have less meaning for them, since they may work on multiple projects within the same time frame.

The organization for each group, the typists and unit members, is logical for their work processes. The problem for the group arises because the shared workspace lacks a common information structure for the groups' documents. Most of the users employ a location-based finding strategy for documents (Wulf, 1997) and some unit members reported that they could not find documents among the vast array of information in the shared workspace because the system supported only the writing office view. One unit member describes his perspective:

For me, the subject is the most important. Plus additional information. It answers the question: what is inside? It's easier to find. The date has to do with the order of the [workspace]. The subject is what tells me the content. It's important for me that the subject tells me what's in the document, and that the reference code is precisely written. The subject is important when we look for an old document. I need subject [field], content, and reference code.

With different file structures in use between the typists and unit members, how are documents exchanged between the groups? The method is basically ad hoc. As one typist reported:

J has many subdirectories. Each have their own special names. When a document comes from $\mathrm{J}$, it is very clear to us where the document should be placed 
back - she writes it on the paper document. ... However, we can't pay attention to and can't keep track of which subdirectories everyone has. When I get exact instructions where to lay a document, or when I know where it goes, then it is not necessary to think about where the document goes.

[A unit member]: They put the documents back in my folder. F [typist] knows this already. It says my name. I have only one level. It's always clear for me where it lies. The newest version always lies on top. The others have something else. $\mathrm{N}$ has many levels.

Thus, each user must specify in which directory the finished document should be placed back into. This unit member is an exception for having one level in his file structure. The solution works fine for some individuals who are careful about specifying locations, but breaks down when this information is not provided to the typists. It is extra overhead for the typists to determine which subdirectory the finished document must be placed into. In contrast, the method used for exchanging documents intragroup, within the Unit, is more uniform, i.e. in task specific folders.

The contrast in the use of the shared workspace by the heterogeneous groups is evident in other respects. First, the typists and Unit members have different needs for notification:

[A Typist]: After returning from vacation, it's not relevant for us in the typing office to know what has happened in the shared folders.

In contrast, it is important for unit members to "catch-up" on work missed during absences since their tasks are interdependent, e.g. collaborative writing and responding to citizens' requests. Thus, they need to know if information has changed. Renaming and erasing documents are also done differently:

Renaming, erasing - that comes less into question for us [typists]. Who should erase a document, that should come from the unit. I don't do that at all with PoliTeam. The other directories, we clean them up a bit when there are too many. But since in PoliTeam, each person has their own directory, I don't go into another person's directory and clean up. If we create a document that's similar, or a new document under another name, then we can erase it.

It is interesting to see that for some operations, implicit conventions have evolved naturally. This typist has indicated that it is logical that the unit members are responsible for doing certain operations such as deleting documents: this decision is based on content.

\subsection{AN IMPLICIT CONVENTION THROUGH PRECEDENCE}

Although the two subgroups implicitly adopted different conventions, one convention that all the users did adopt was that of maintaining private workspaces. Its use for preparing drafts, and storing documents was quite similar across users. No one explicitly discussed borders of public and private workspaces. Private workspaces 
were respected; the users reported that no one wants to search or look at anyone's private workspace, and conversely wants no one to search theirs, including persons acting as substitutes. It must be emphasized that this convention violates the policy of the GGO, which states that all work in the ministry must be public.

A precedent for all group members existed before the introduction of the system: the use of private work areas. The users described how this influenced their use of the current convention:

Private areas should be protected. It's good that I can't search L's desk. This corresponds to our earlier experience with our real desks.

There are certainly private areas here. Such as my private workspace. If someone looks for a circulation folder here [pointing to the in- and out-box on her desk], they can search in the out-box, but not in the in-box. Similarly, what lays on my private desk, that is private.

It [the distinction between public and private areas] was made very natural and implicit.

That is one of the basic conventions that protects the workers. Also when someone develops something on their [private] workspace, then it's relevant when it's put in a folder and it's accessible to me. Before [then], it's not relevant to me. It's their thing, I don't look at it and say, what have you written for the first three sentences? It is a fundamental convention and it has a protection character. On the one side, you want to know the information that someone has, but on the other side, you have to keep in mind that it's a private sphere.

It was obvious to us. The system is an exact technical reproduction of our work. That's the charm of the system. You observed how work functions in the Ministry, and then you tried to reproduce it electronically. So it's no wonder that conventions used in our normal work are carried over.

\subsubsection{Explicit and implicit means for adopting conventions}

As the above examples show, conventions can be formed implicitly when precedents of prior conventions are the same for all group (or subgroup) members. However, conventions can also be formed through explicit agreements when a situation is recognized as a coordination problem and a solution is then actively sought. For example, if several people want to use a handbook, and only one copy exists, a convention is formed to regulate turn-taking. Explicit conventions (see Waldenfels, 1994), can take the form of agreements, rules, or even laws, and may be introduced by the group itself, or else by an agent in the group, or the organization (Finnemore and Sikkink, 1998).

Conventions to regulate non-verbal communication are naturally developed since individuals are attuned to others' facial expressions and change their behaviors accordingly (Bakeman and Gottman, 1986). Conventions to regulate artifact 
use within a group are naturally developed as people observe how others handle artifacts. Ethnographic investigations have shown that actors adjust their behaviors depending on others' actions to stimuli, e.g. using telephones in a dealer room (Heath et al., 1993), using paper airstrips in air traffic control (Hughes et al., 1992), or interacting in control rooms (Heath and Luff, 1992). A simple and elegant example of how common information influences behavior and leads to conventions can be found in a protocol of children at play, described in Bakeman and Gottman (1986, p. 41). Two children, coloring next to each other begin as individuals playing in parallel with crayons. Soon, while observing the colors that the other is using, the play evolves into joint use of the stimuli, and a convention: "You want all my blue?", "Yes. To make cookies. Just to make cookies, but we can't mess the cookies all up".

The above-described examples illustrate how implicit conventions can be formed through modeling or emulating the behavior of others. People may consciously or unconsciously adopt "models" of behavior of other group members (Bandura, 1971). One reason this may occur is that members may believe that uniformity in procedures is necessary to establish in the group, in order to help the group achieve its goals (Festinger, 1959). Falling into a smooth rhythm when canoeing is an example of modeling behavior that occurs implicitly. Or when one visits another country for the first time, e.g. to attend a business meeting, then one watches the actions and behaviors of the others to discover what is appropriate. Models make it easy to learn.

Another means for forming implicit conventions is when precedents are established from analogous situations. If group members share the same experience of a previous convention, then this can be applied as precedent in a new situation. For example, in a new work team, members may apply a precedent of democratic decision-making, which all experienced in their former work teams. The problem is that different precedents create ambiguity in the group and would not result in a uniform convention. If some team members had previously experienced an autocratic decision-making process, then there would be ambiguity in the group over which convention to use. The group would first need to sort out their differences and decide upon an appropriate scheme. In addition, the more similar the current situation and precedent, the easier it is for group members to map the analogy.

\subsubsection{The role of feedback}

Feedback plays an important role in the development of both implicit and explicit conventions by shaping behavior. Feedback can function in two ways: members provide information to each other on what behaviors are appropriate or inappropriate. It can also serve to provide reinforcement for behaviors that are carried out. Positive feedback strengthens responses, for example through praise or encouragement, whereas negative feedback, for example through criticism, stops or reverses a behavior. 
Due to selective processing, the stimuli provided by a face-to-face work group can have a large impact on group members' attitudes, behaviors, and beliefs (Weick, 1969). Again we see how the proximity of actors plays a major role. A variety of stimuli can serve this purpose with face-to-face actors, e.g. facial expression, gesture, or verbal response. By selectively using such stimuli, groups can achieve a number of purposes with feedback: to socialize the members, to create uniformity, to produce diversity, as in roles, as well as establishing norms and conventions (Hackman, 1976).

Some research suggests that negative feedback has a stronger function in shaping convention behavior than praise or reinforcement, as for example when a convention is violated. Numerous studies have shown that group members will go out of their way to coerce deviant members to conform to the group norm (see Levine, 1989, for a review). In fact, it is essential that the stimuli to shape behavior be readily available to the group. The better a group can effectively control and use stimuli that can shape behavior, the more it can eliminate violations or deviance among the members (Hackman, 1976). Thus, in face-to-face groups, where stimuli for feedback purposes is readily available, the group has at-hand means for effectively controlling violations of conventions. In groups not in close proximity, there is far less opportunity for providing immediate feedback for shaping behavior, and for controlling deviance.

Feedback such as notifications, can be quite powerful as a means of shaping behavior in groups. Not only can it be used to control deviance, and to ensure that conventions are followed, but it can also increase the learning efficiency of the group. For example, through feedback, group members have been able to increase their problem-solving efficiency and role-learning (Smith and Kight, 1959).

Of course, a number of other factors can modify the effects of these explicit and implicit mechanisms in influencing conventions, such as the status of those giving feedback, those in the group serving as models, and external pressures such as reward structures and task complexity. The social influence within a group plays a very strong role in forming and maintaining conventions, and in physically collocated actors, it is relatively robust. Even when normative pressures are minimal, it has been demonstrated experimentally that social influences can still be quite strong (Tajfel, 1969).

\subsection{LACK OF COMMITMENT TO CONVENTIONS}

In contrast with the implicitly formed conventions, several explicit agreements on conventions were made by the PoliTeam users, and in most cases, these agreements were violated. The first case of explicitly forming group conventions occurred to address the conflicting naming conventions. The conflict was discussed in the second workshop, initiated by the user advocates six months after system use. Several solutions were discussed, and a proposal was made for maintaining the typists' naming and storing conventions. The group was to use a third level in the 
information hierarchy, to file documents according to the task. However, most unit members did not follow the conventions, as the typists describe:

The naming conventions still bother me. Because others [unit members] have problems with the standardized names. ... A few follow the conventions.

With the naming conventions, we haven't made any progress. We know we have only 8 letters to use, and despite this, we still use more than 8 letters. The printout therefore looks very similar ... Can one actually implement something? We have done that with the reference code. One could also do that in principle with the naming conventions. ... Naturally everyone would prefer to work their own way.

The unit members describe:

With the naming conventions, there was difficulty with the typists.

Naming conventions, reference code, and subject area, I always violate. I give file names that seem to fit.

The naming conventions, what are these? We first write 57 [a pseudonym of the unit shared workspace], then the reference code, which completes it.

This, of course, is not the correct naming convention.

The typist above has requested technical means to help with conventions. However, in afterthought, the typist spoke against such a method, stating that it would restrict the freedom of the other users. Technical means were implemented to prompt users to follow a convention of entering a file code on newly created documents which is important since it provides a common reference for electronic documents. Yet all but one user fail to type it in:

We [the writing office] give no file code. We type in 0000. Maybe they [the Unit members] give the correct file code afterwards.

If I know the file code, I give it. Otherwise I use a fantasy number.

They don't type in the right file code. I must correct them. I must sort the documents into the right archive. And it must correspond with the file code. And that's annoying.

Other convention violations also occurred. In order to provide all users with access to the latest version of documents (the writing office especially needs to retain access to the latest electronic version of the document for further processing up the ministry hierarchy), an explicit agreement on a convention was set in the second workshop: a document must not be removed from a shared folder. However, in practice, many Unit members would drag the document out of the folder shared with the writing office into their task specific folder, violating the convention:

It gets on my nerves, when people don't work on their things in the writing office shared folder. In the case of substituting, when you want to get these things, then it's really difficult. 
Another violation was observed with the use of a shared address list. An explicit agreement on a convention was set which required that all members update the list. The users had methods for keeping addresses before PoliTeam, such as storing lists in a drawer, and their personal lists provided most addresses for them, at least enough that they were unwilling to follow a group convention. As one user explains:

It doesn't function yet, though, since we don't have conventions for it. Each one does something else. It functions only when all the users use this distribution tool. An address list functions only when all write it into a central place. It doesn't work when each one keeps a list in parallel.

Some users reported that the shared address list did not exist before PoliTeam, and they did not have previous conventions to carry over to it. According to one user:

Not everything can be carried over into the computer work ... Before, the address lists were organized so that you had it lying in the drawer in your desk. Now, it's being moved from the drawer in your desk into the public workspace as a share. Naturally, technology brings changes here. But it's a big advantage, that we can bring it from the private space into the public space.

\subsubsection{Influences on commitments to conventions}

The users had great difficulty in following their explicit agreements on conventions. Commitment by a group to conventions can be influenced by several factors: whether the convention is accepted by the group, the payoffs for group members, and the amount of social influences in the group.

One of the main factors according to Finnemore and Sikkink (1998), of whether a group will commit to a convention is whether the convention crosses an acceptance threshold in the group, where a critical mass is reached. One way to achieve an acceptance threshold is through the persuasion by some agent, e.g. a manager. A second way to cross an acceptance threshold is if the convention becomes institutionalized. The conventions may be mandated by a senior level manager or may appear in the organization's set of rules.

Finnemore and Sikkink propose that when such an acceptance threshold (i.e. a critical mass) is reached, a cascade process follows which leads to the internalization of a convention. At this point, conformity to the convention occurs, and the convention is incorporated as a habit. This raises an open question about convention use. If a convention should become a habit, i.e. followed rotely, then the choice to conform to the agreement is no longer being made. When events are dynamic, as in the case of emerging work processes, it is not clear whether such internalization would hinder the flexibility needed to adjust conventions to change.

From a game theory perspective (e.g. Axelrod, 1984), conventions would be adopted by the group if their use results in a higher payoff than by not using them. In physically collocated groups, the payoff for the group may be evident 
to all members. However, in distributed groups, the payoff for the individual (in following an individual routine) may be more salient and more beneficial than the group payoff.

Social influences can reinforce commitment to a convention. Waltz (1979) describes such influences on convention use as emulation, praising conforming behavior, and punishment for deviating from the norm. The power of peer pressure cannot be underestimated, and in experimental settings, its effect on inducing conformity to norms and conventions has been strongly demonstrated. Even in the face of what appears to be obviously wrong judgments, people will make judgments that conform to the group opinion, rather than deviate (Asch, 1956). Yet these studies have been carried out with actors who are face-to-face; inducing social pressure in a distributed group is difficult to achieve.

\subsection{SUMMARY OF CONVENTION USE}

I have defined conventions for electronic work as agreements for local control of the system to accomplish work. The long-term case study illustrates that a wide range of transactions needed to be regulated by conventions, which can be roughly categorized into: communication transactions, e.g. who to inform about document changes; data processing transactions, e.g. who should be the document owner; and decision-making transactions, e.g. who is responsible for a document, or for maintaining the order of a workspace.

The experiences from the case study can be summarized into the following points concerning use of conventions in the group's electronic work:

1) The group needed to have some degree of experience working together with group functionality before the consequences of other group members' actions were recognized, i.e. coordination situations, triggering the recognition for conventions.

2) Most conventions did not become established implicitly; explicit conventions were formed in a face-to-face setting outside of the group's daily work environment.

3) Conventions logical for subgroup work became established.

4) A convention used in paper-based work by all members, and for which there were clear similarities to electronic work, was adopted and followed implicitly by the group.

5) Explicit agreements for conventions were not adhered to.

When the agreements on the conventions were not followed by the group, it resulted in overhead and process loss, such as requiring time to search for files. Reasons that contributed to the group's difficulty in forming and following conventions will be discussed in finer detail in the next section. 


\section{Discussion}

\subsection{DIFFICULTIES IN FORMING CONVENTIONS IN ELECTRONIC WORK}

If we consider Lewis' description of conventions as a normative model, i.e. a standard by which we can evaluate convention behavior, then the group in the case study rarely followed normative face-to-face convention behavior in their electronic work. The paradox is that the group formed agreements for conventions believing that it would improve their cooperation. Yet in their actual working practice these agreements were seldom adhered to. In this section, I discuss in more detail why the group did not follow normative convention behavior. My claim is that the group members were working in conditions where it was difficult to learn about others' activities, to engage in ongoing articulation, and above all, to change individual behaviors.

\subsubsection{System development and learning over time}

The first point mentioned about convention use was that the group needed to have some degree of experience working with the functionality before they could recognize coordination situations in their work. Why did it take so long? Certainly the workshop discussion which took place several months earlier alerted the users to the issue of conventions. But a contributing factor could also have been the design approach which may have served to inadvertently reinforce particular patterns of system usage, patterns which prolonged the discovery of coordination situations. The design approach was an evolutionary cycle (see Section 2), where system requirements were gathered in the course of the users' actual work. Through this gathering of requirements, the system design evolved in different stages. The basic idea is the following: the stages of system design mirrored the evolution of the system usage.

The requirements resulted in the following system modifications (see Prinz et al., 1998 for further details). The first version provided a stable system for the users to work with, including providing email, a personal electronic desktop, an electronic circulation folder, and a shared workspace. Small modifications to the existing functionality and additionally user-specific document processing were incorporated into the second version after about one year. The main changes incorporated into the third version were an integration of the system with the organization's in-house IT infrastructure, along with features to support managers. In the final version, the main system changes addressed the cooperative needs of users: e.g. a basic awareness mechanism (Sohlenkamp et al., 1997), and institutional mail inboxes. Figure 2 shows these basic system stages alongside the users' rough learning stages.

In the first stage, we see that users were experimenting with the basic functionality. Once they learned it, they then began forming individual usage patterns, such as structuring information in personal desktops. From this user behavior, the user advocates obtained requirements that addressed individual aspects of work, 
which in turn enhanced individual functionality. After some months, more and more group functionality was set up and tried out, and the user advocates in turn identified refinements concerning the group functionality, which in turn enhanced group functionality in the evolutionary cycle. It was only after the users acquired experience with, for example, the use of shared folders, that they began to recognize that others' actions brought consequences. It was during this time that the workshop took place where conventions for system use were discussed (conventions for naming files and not removing shared documents from the shared workspace were discussed at earlier workshops). Since this was raised as a major requirement, effort was then made to modify the system to support conventions. Syri (1997) proposed enablers and mediating objects which incorporated the flexible use of some conventions.

What can we learn from this interrelated pattern of system development and learning?

First, a lesson is that the approach to learning user requirements was valuable; many requirements could not have been foreseen, and could not have been obtained without observing the system in actual work (Prinz et al., 1998). Every modification to the system results in a change of the "tangible artifact" that the users are working with to evaluate their needs (Ballay, 1994). The point here is that it would have been difficult for users to theorize about, or anticipate in advance, that they would need conventions. In hindsight, the stages of use and system development follow in a logical order: supporting first individual, then group needs. The users could not have seen the need for conventions without first experiencing group work. By enhancing the system based on the users' requirements, which was based on current use at the time, it was reinforcing the users' patterns, rather than promoting the users to evolve in their usage. In sum, what happened was a cycle: the system development was driven by the users' patterns of usage, and implemented requirements to support that current pattern of usage. Could coordination situations have been recognized earlier with a different design approach? It is hard to know in hindsight, but my guess is yes.

Second, a broader lesson learned here is that the designer plays an intricate role as group facilitator. That is, not only does the designer implement modifications into the system, but the end effect is that these system changes influence users in particular patterns of usage. For example, introducing technical support for conventions should facilitate users into developing conventions needed for their electronic work. Designers need to consider how system modifications in a groupware system can be made in a way to promote congruent patterns of usage for the entire group.

\subsubsection{Limited communication in distributed groups}

The second point about convention use in the group is that conventions did not become established implicitly, but rather explicitly. This suggests that another main reason for the group's difficulty in forming conventions was due to the limited communication of the members about their work. Whereas physically 


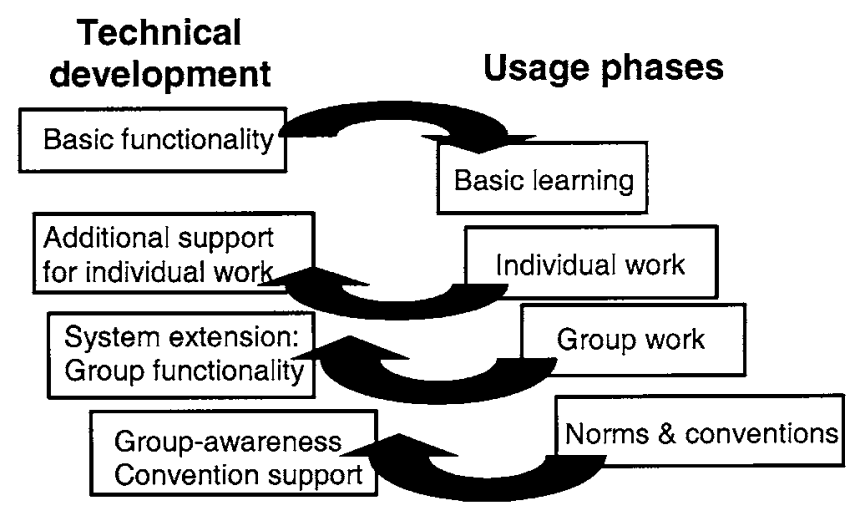

Figure 2. Relation of development of system and usage phases.

collocated group members can easily learn a great deal of information about others' work simply through peripheral observation and conversation, the PoliTeam group communicated about their work mainly through email, an occasional telephone call, or with the typists, through automatic notification when a document was ready. As discussed earlier, it is the common information available to the group, about artifact use, behavior, communicative signals, and environment that serves as the basis for forming conventions. In the case of the PoliTeam users, the group had to reconstruct this information through their intermittent communication.

Rather, the workshops, where the users met in structured meetings every six months, were a means to supplement the users' communication about group work, and in these the users did focus on discussing shared object use. In the third workshop, which took place after one and one half years, a serious discussion on a wide range of conventions took place, initiated by the Unit leader. The insightful Unit leader pointed out in this workshop discussion that the user group needed to develop new cultural thinking in their electronic cooperation: using a groupware system involves adhering to common group agreements.

However, to develop new cultural thinking in a distributed group requires more regular communication than meeting face-to-face once every six months. It appears that the workshops did play an important role for conventions, in terms of raising it as an issue. The lesson learned is that agreements formed in an external setting are difficult to maintain in the course of actual (distributed) work.

This experience illustrates a conflicting set of expectations between the design team and users. The work to make the conventions work was actually delegated by the users to the design team, as opposed to being self-regulated. This was not the intent of the design team; the intention instead was that the workshops would facilitate thinking about conventions, and that the users would take the initiative (Prinz et al., 1998). But interestingly enough, in the course of their daily work, the users did not discuss conventions. In fact even to schedule additional time to 
address the topic of conventions was not done due to the overhead, as this user reports:

We must simply try. I can't imagine that there is a scientific method to use. We are forced to formulate them [conventions]. What we can do, is help with that. And for us the conventions are also a help.... If I had time, I would spend two days working on it. But it's a question of time for us. If we would meet for a day workshop, then that would be good. It's the preparation that's hard. We need a meeting to formulate them.

Articulation is needed in order for a group to achieve a standard representation or convention for handling boundary objects (Gerson and Star, 1986). Thus we see a dilemma: articulation work is necessary, but due to the overhead to meet and communicate above and beyond actual work, it was neglected by the group on its own. Through extrinsic means, i.e. workshops facilitated by the design team, the users participated in articulation, but articulation did not become an intrinsic process in the group, in the course of actual work. This experience raises the requirement for enhanced communication in the group to maintain a constant and easily accessible channel for articulation.

\subsubsection{Conflicting perspectives in subgroups}

A third point discovered about convention use was that conventions that were logical for subgroup work were followed. Thus, although information can be common to a distributed group, different subgroups can develop different conventions for its usage, instead of forming a common group convention. Especially when cooperating partners cross organizational boundaries, the same object or piece of data is subject to different specialized activities, opinions, perspectives, and interests, which can lead to different handling. Whereas members of the same work team may have developed similar interpretations for some objects, very often cooperation occurs between members of heterogeneous groups, whose perspectives can be quite diverse.

Through applying different precedents, the typists and unit members adopted conflicting file naming and storage conventions. Before PoliTeam, the unit members used a task-based storage scheme for paper documents, with the registrar department; with PoliTeam, documents were stored in the shared workspace in task-specific electronic folders. The typists used the same name and date conventions with PoliTeam as with documents that they previously stored electronically in a house system. Conventions from previous work, which were appropriate and logical for different subgroup work practices, were not congruent when the subgroups cooperated together. For the unit members, naming and storing documents according to task made sense for their work practice, and for the typists, naming and storing documents according to the unit member was logical for their work practice, since they were concerned primarily with the owner of the document. 
Users can face difficulties in forming conventions when they hold different mental models of their work processes, the system, and its goals, which Orlikowski and Gash (1994) refer to as different technological frames. And if different group members possess different technological frames, it follows that their perceptions of each others' behaviors may not be accurate. This type of egocentric view is expressed by Schutz (1970, p. 229): "each expects that the other's interpretive scheme will be congruent with his own". The typists and unit members seemed to have behaved according to this belief.

Evidence for different technological frames of the typists and unit members were obtained through interviews. Mark and Mambrey (1997) reported that the typists and unit members had different models about their cooperation, the organization, and their work, all of which can affect the users' perspectives and handling of the shared objects. To the unit employees, typing is a mechanical process and they felt that their interaction with the typists was not cooperation. The typists, however, felt that their task was a necessary part of the groupwork. This difference in notions of cooperation could have contributed to the unit members' lack of commitment in following the naming conventions, since they may not have viewed the typists' as being full cooperating partners. This experience illustrates that conventions must be established on a basis of common assumptions among all group members, concerning work, and system use.

\subsubsection{Regulating the use of flexible media}

Another contributing factor to the difficulty in forming conventions was due to the flexibility that the groupware system offered. The need to regulate interactions was related to the design approach, which intended to supply a medium for cooperation, as opposed to implementing prescribed cooperation mechanisms (Prinz et al., 1998; Bentley and Dourish, 1995). The flexible cooperation media included both electronic circulation folders, where plans for work sequences could be configurable, and shared workspaces, where material could be flexibly stored and accessed, for a number of different purposes. But the provision of such flexible media presented a paradox for the users, expressed in the words of the Unit leader:

There must be ground rules established for working together and dealing with the groupware. The culture is lacking to be able to handle this problem with the new technical possibilities. The stronger the technical flexibility, the more rules must exist for how we can handle this.

A shared workspace, through its unstructured nature, can be adapted by the group in any number of ways to fit its requirements. As Bentley and Dourish (1995) argue, a system need not incorporate a representation of a group's activities in order to support it. Yet while flexibility enables a number of different working styles, it imposes a burden on the group to regulate its interdependent activities.

The unstructured nature of the shared workspace compounds the problem of forming conventions. The features available define what actions are possible, but 
the system design itself does not prescribe a set order or method for using them. A shared workspace is characterized by properties that Hewitt (1985) describes to be generally true for open systems. First, they are continually changing and evolving; new information is continually being put into them, new file structures are being developed, and aging information is put into new folders or erased. Second, such workspaces do not have direct access to internal information from other users. In other words, one sees only the results of the actions, but may not gain enough information about other users to help one infer reasons behind the actions (Schutz, 1970). Third, in many cases they involve decentralized decision-making, which introduces problems arising when groups do not have a leader or alternative mechanism to attend to events, to measure them, and control them (Schein, 1985). Fourth, shared workspaces, and especially those whose usage cross organizational boundaries, are often used by those having different perspectives and even conflicting beliefs about work. The shared objects in this case become boundary objects that require a special type of reconciling interpretation and management. And lastly, shared workspaces do not meet the assumption of a closed-world which imposes the additional burden for users of needing to take external information into account.

\subsubsection{Discontinuous cooperation}

Another explanation why the group had difficulty to form conventions, and to hold to agreements, is because the PoliTeam members' cooperation was not continuous. This made it difficult to learn their interdependencies, to learn where coordination situations lay, and to provide timely feedback. An example of norms ${ }^{1}$ developed during continuous cooperation is discussed in Ackerman et al. (1997). Due to the continuous nature of the interaction, the group members' actions and feedback were contiguous in time, and the members developed the norms quickly.

The cooperation of the PoliTeam users was discontinuous, i.e. the users were not continuously working with the shared workspace. Rather, they would work on their personal desktops, and use the shared workspace to exchange and store information. Although sometimes group members would give feedback immediately when they objected to another's action, often feedback was given long after the action, or not at all. Communicative behaviors may in fact have a certain period of time relevance for partners. That is, behaviors have a time decay, and this is modified by certain factors, e.g. the type of behavior, and its salience. Models incorporating time decay appear quite robust in explaining a number of basic faceto-face communicative behaviors (e.g. Frey, 1975). Although it is unclear how such models can generalize to electronic interaction, it does seem plausible that notification of others' behaviors must be presented at points when it is relevant for the receiver. This can optimize learning for the recipient of the information. Thus, the discontinuity of cooperation and feedback, plus the flexibility of actions allowed by the system, made it difficult for the users to learn relationships between behaviors, and consequently to form conventions. 


\subsubsection{Common precedents from prior work}

A fourth observation of convention use was that the same precedent of a convention was applied by the whole group to the electronic work. Whereas the typists and unit members applied different precedents of naming and storing conventions, it can also be shown from this study that when the precedent of a convention is the same for all group members, and when the mapping of the analogy is clear for all, such a convention can be carried over to electronic work and applied by the whole group. This was evidenced by the convention of maintaining private and public workspaces. Applying analogy to technology use is a valuable learning tool, since people try to understand new processes in terms of a conceptual framework that they already know (Carroll and Thomas, 1982). Before PoliTeam, the users had a clear distinction on their physical desks between public and private workspaces, e.g. private spaces being in-boxes or locked drawers.

In cases where no clear precedent for a convention exists for electronic work, it becomes difficult for users to develop conventions implicitly. When the workspace established a new connection between Bonn and Berlin, the usage of the workspace was not yet clear for the users. Orlikowski (1996) cites an example of how specialists, because of their experience, were able to recognize the need for some conventions to fit an emerging work process. However, because the work practice using the system between Bonn and Berlin needed yet to be refined, the precedents gained from past experiences with shared workspaces could not be easily applied.

\subsection{COMMITMENTS TO CONVENTIONS}

Up to now, I have primarily discussed conditions that made it difficult for the group to form congruent conventions. The last point that was observed about the group's convention behavior was that explicit agreements on conventions were not adhered to. Violations among agreements per se need not be detrimental to a task, such as in responding to changes in the environment (Beck and Bellotti, 1993) or if due to "productive laziness" (Rogers, 1993). But in the PoliTeam case, not following the agreements for conventions brought additional work and annoyance to others. Let us revisit some influencing factors for convention commitment (section 2.6.1), in terms of the PoliTeam user experiences.

A convention may cross an acceptance threshold if it becomes institutionalized. In the PoliTeam case, the organizational platform, which supports the ministry's formal GGO procedures, did not determine conventions for the group. First, the users did not conform to the GGO when they first defined their user requirements. Second, many conventions needed for the electronic work are new, and cannot be based on the prior GGO specifications for paper-based work. Third, as a pilot group testing a prototype, their work with the groupware system was of a different nature than typical ministry workers, and the organization did not intervene with rules of operation. In fact, there are few examples in distributed electronic work where conventions have become institutionalized. Prohibitions of flaming and rude 
behavior are examples in some collaborative virtual environments, which results in violators being disconnected.

A technical implementation might be considered a way to institutionalize a convention. With PoliTeam, the convention to provide a file code was formally coded into the system: a prompt was given, and users had to enter a number. Yet despite this implementation, the users did not follow the convention, but rather typed in a fantasy code. The users were not willing to do the work to look up the proper code, and instead became "free riders" of the system, expecting that another user would supply the correct file code in the course of the document's use. This failure of the technical prompt to promote the convention behavior demonstrates another gap between the designers' assumptions of user behavior and actual user behavior.

The Unit leader could have been a persuasive agent to help the convention reach an acceptance threshold in the group, as he was a strong advocate for group conventions. Yet he continually stated that he did not want to issue a mandate: he made sure to communicate that he wanted the group itself to promote convention usage in "subtle" ways. Nor did the design team want to force the users to accept a convention; they wanted the users to self-organize.

Payoffs, which influence convention adoption, may be uneven among group members, especially in inter-organizational cooperation. For the PoliTeam users, maintaining the conventions would result in uneven payoffs in the group. For example, the group was asked by a superior to agree upon the naming convention of the typists. For the Unit members, it required effort to follow the naming convention, since this involved renaming their files to conform to a new convention, which was not even logical for their work practices. In fact, the one Unit member who reported using "file names that seem to fit" did not even follow the naming convention of those in his own subgroup.

An imbalance in the overhead and benefits existed for the group members in following the convention of updating the shared address list, similar to what Grudin (1988) found with shared calendar use. One user described that he viewed the address list as a personal item. In fact, this user would have benefited by having other users update and add new addresses.

Social pressure, which can reinforce commitment to a convention, is weak in electronic work since everyone's activities are only partially visible to others. This lack of visibility (and related anonymity) shield against social influence, and increase the chances for convention violations and free riding to occur. This lack of social pressure was evident in the case of the PoliTeam users during their electronic work. They rarely received praise or punishment for their actions.

The PoliTeam users never built up experiences where everyone conformed to an (explicitly-formed) convention. As Lewis (1969) points out, without such a set of experiences, the group does not develop expectations that others will conform in the future; the expectations are a core factor which leads to commitment. Because the usage of the shared objects were not visible, it was not clear to the users who 
had followed the conventions. In particular, knowing who accepts the convention is also critical, such as whether it is the Unit leader and head typist, or a part-time employee. Thus, a basic pattern was set early in the group of nonconformity to conventions.

\section{Awareness support for conventions: Establishing feedback}

The difficulty in forming and following conventions in the case study group can be attributed to a long list of factors: the lack of clear precedents, different perspectives among group members, a large set of actions possible in the shared workspace, limited communication, the reinforcement of certain (individual) system behaviors, constrained social processes, discontinuous cooperation, and uneven payoffs. The actions of a distributed group are a stark contrast to how a physically collocated group forms conventions: by monitoring each others' behaviors and efficiently adjusting their own behaviors either through explicit or implicit means. All of these factors in the distributed group made it difficult for the users to integrate articulation into their actual work, which is necessary to form and manage conventions. The empirical results call for a specific set of awareness information requirements to support such an articulation process, and these must be further qualified.

The need for supplying awareness information to support cooperative work has been discussed for some time in CSCW. One of the main goals of providing awareness information has been to make others' actions in the groupware application perceivable. The intent of showing presence and activities, has been proposed to provide a group context for one's work (Dourish and Belloti, 1992). Presenting distributed members with the same screen views (WYSIWIS) helps coordinate synchronous work (Stefik et al., 1987). Awareness indicators have included widgets in the form of radar views (e.g. Baecker et al., 1993), auditory signals (e.g. Gaver et al., 1991), and graphical indicators (Tatar et al., 1991). More recently, Gutwin and Greenberg (1998) have proposed awareness indicators that can meet the demands of the tradeoff between individual and group work. While awareness indicators appear promising, and even necessary to achieve the aims of synchronization, guiding subsequent actions, and providing a sense of a group environment, I also propose an additional function that awareness can serve: awareness information can help a group to form and maintain conventions by reducing the requisite effort.

In the context of supporting conventions, the goal of awareness information is to help a distributed group develop and maintain the appropriate behaviors that are needed to form and maintain agreements about work. I propose the following definition: awareness information is the raw material for team members to be able to manage local control over their work. As with the definition of conventions that I proposed, I use the word "local" in contrast with a more global management of work, which coordination mechanisms would support. Although awareness certainly contributes to the global management of work, my focus is on how it can support conventions. Dourish and Belloti (1992) originally proposed that by under- 
standing the activities of others through awareness information, one can construct a context for their own work. But not only does awareness enable one to construct a context for individual work; it also enables group members to conduct their work with others, as Grinter (1996) found with software developers. Awareness would provide users the information that they need for them to form and follow conventions.

Information about system use is "raw" material, and must be interpreted. Awareness information thus needs to trigger an active information processing by the recipient. Why this emphasis on active information processing, as opposed to information that could be effortlessly processed and integrated into work? Certainly low overhead awareness information is also a benefit, such as that which is geared to a particular context of use (Fuchs, 1999). But active information processing implies that it should function not just as updates notifying others about object use, but as information that can promote learning about, and shaping of, group behavior. Learning occurs best with active, as opposed to passive information processing, and forming conventions involves learning about the group activity. In physically collocated groups, learning about the group is also an active process.

Awareness information can promote learning about two aspects of distributed groups. First, it can promote learning in terms of the task: e.g. how others are organizing common information, individual methods for access rights, and how information is archived by different users in public spaces. In the short term, such awareness information aids group members in making local decisions on how to proceed with their work. For example, they can be informed whether their practices are discrepant with other users. In the long term, awareness information can be stored, e.g. in an organizational memory, as Bordetsky and Mark (in press) propose. Such accumulated information can be used by the group for articulation purposes. This information can either be used to form explicit conventions, or may even work to promote implicit conventions (via modeling), although both hypotheses would need to be tested. Secondly, awareness information can promote learning about social aspects of the group, in particular in developing appropriate rules of interaction. In the short term, this information can inform users on making reasonable local decisions on how to interact, such as when to contact someone, or who to contact for a certain type of information. Again, in the long term, this information can be stored, as in an organizational memory, to help the group in managing conventions for interaction.

But conventions serve an additional purpose to governing the interaction and use of artifacts. Knowing the conventions helps group members interpret behaviors and states of affairs in the group. For example, papers that are placed in a pile on a colleague's desktop indicate that they are public and can be looked at, but those moved to a closed desk drawer become private. Thus, conventions not only help group members to regulate interaction and the use of artifacts for coordination purposes, but they also provide a framework to interpret and predict the group behavior. In other words, conventions provide a framework for awareness. 
Following this definition, I now describe, based on the empirical results, requirements that awareness information needs to fulfill in order that it can be utilized to promote learning and development of appropriate task and social behaviors in the group. I focus on the role of feedback, as I have discussed earlier that feedback has been demonstrated to have a strong impact on shaping group behavior.

\subsection{FEEDBACK AS COMMUNICATION CHANNELS}

Even when explicit agreements about system usage can be formed, the agreements may not hold, as in the case of the PoliTeam users. Feedback can serve to remind other users if their behavior is not appropriate, but in the case of the PoliTeam system, a feedback channel was not included in the system, and the feedback at the time of usage seldom occurred.

Robinson (1991) discusses the value of providing for both formal and informal communication in the design of a shared application. Formal communication can be expressed through the system via information-structuring, e.g. through a shared editor or hypermedia structures, and the voice link is the informal aspect of communication. Yet in the PoliTeam case, even discussions at the workshops were "one-step removed" from actual work. Informal communication needs to be closely integrated with the use of the system. However, asynchronous work poses a difficult problem for achieving effects of feedback. The problem is that the contexts of the sender and the recipient of the event information are different. In the case of the PoliTeam users, the Unit members often worked on different tasks in parallel. Providing informal communication means is ideal in theory, but in practice, grounding the conversation in a common context will be difficult for both partners.

This calls for a specific role of awareness information as feedback, to complement the double-language facility of shared object use, in two respects. The first is to restore the context for both actors when feedback is given by clarifying certain vital statistics: which objects are of concern, who has handled them, and in the case that a convention is being violated, information about the convention needs to be accessible. The second point is to make salient "intuitive" access points for communication. For example, one can specify to be notified when a document has been removed from the shared workspace (a convention violation). The goal of making such access points "intuitive" is so that discussion concerning shared object use can occur at a time when it is relevant for learning about behavior, e.g. at the time a convention is violated.

\subsection{FEEDBACK AS RELATIONS BETWEEN ACTIONS AND EFFECTS}

It is difficult for actors to make associations about actions that are not contiguous in time. For learning to take place (following classical or operant conditioning 
theory) one must be able to make associations between different stimuli. Further, all stimuli must be clearly identifiable in order for relationships between them to be understood. In single user systems, actions are contiguous with effects. With groupware systems, in asynchronous work, the effect of one user's actions will not appear contiguous for all users. For the users of PoliTeam, in most cases the consequences of their actions on other users were not visible. The discontinuous cooperation, along with the fact that the shared workspace afforded a large set of possible actions, made it difficult for users to pair actions and effects of system use. Thus, consequences may have been visible, as in the case of a document removed from the workspace, but the cause of the effect was not visible.

This calls for the requirement of reconstructing the relations between actions and effects for users, so that they become aware of the consequences that their actions have on others, and to learn what system effects other users' actions bring. If a convention has been already set, it may be feasible for users to learn only about negative consequences, i.e. if their action will result in a convention violation. This requires a mechanism that can store information about conventions, and that can be accessible.

\subsection{ARE GROUP CONVENTIONS IN ELECTRONIC WORK REALLY NECESSARY?}

An approach which contrasts to that of awareness as an active learning device, is to provide a means for subgroups or individuals to retain some individual conventions. Such a mechanism, designed to reconcile different users' views "behind the scenes" acts as a translator. This has the advantage that for some work habits that are logical for their task, such as file organization, group members do not need to change them. The disadvantage is that the group members then lack a common reference, such as file names. This tradeoff between individual and group requirements was addressed by Gutwin and Greenberg (1998) who translated gestures and deictic references into different individual representations. In this way, individual views were maintained, and other actors' actions were mapped onto their views. Another solution was proposed by Simone et al. (1999), to "reconcile" different users' schemas. In those cases when conventions can become algorithmic, such a mechanism would support the correspondences between different names and relations. For example, if two users have different file organizations, when one user requests a set of documents, then the documents would be identified and recontextualized in another user's workspace. Another solution proposed by Dourish et al. (1999) uses context to mediate between different individual customizations.

The solution for such a tradeoff is not clear. The problem is that communication occurs inside and outside the system, which calls for the requirement of a standard group representation. For work processes that occur in personal workspaces, such as file organization, retaining individual views makes sense since they are logical for one's individual work. However, I argue that group representations are needed for objects that are shared, since one's actions have consequences for another user. 
Typing in a wrong file code for a shared document, removing a document from a workspace, and storing information haphazardly in the public workspace are all cases that result in negative consequences for other users. The problem with this division is that it becomes fuzzy. For example, even if file organization in personal workspaces remains individual, and if shared objects that are exchanged are recontextualized, if the objects are later stored in a public workspace, then they become common to the group. A solution where an object can be both personalized and also contain a common reference can become cumbersome and confusing. This issue is still unresolved and remains a challenging problem.

The Unit leader expressed clearly the nature of this tradeoff:

It's a problem of the working method of people. There's always a certain tolerance: a certain openness of doing things and a certain stringency. These are the two poles. That means on the one side we must allow individuality, and on the other side, we must arrange conventions. That's the normal daily working style. Each one arranges their desk in their own way, and that's their freedom. The problem is that we are in an evolutionary process here - we need conventions for our normal contact with each other, our process. We don't have this yet with information technology. We need to find a balance between individual operations and conventions. It is a balance. And it's very central. There are things that must be reproducible. It must be clear that people possibly may do things not according to their individual ideas, because it is an improvement for everyone.... The success of PoliTeam depends on this.

But are conventions really necessary, or can standard group representations simply be formed through technical means, remaining "invisible" so as not to bother users in their work? There are two strong arguments for conventions. The first is that it is an extremely difficult problem to formally capture the wide range of conventions that a distributed group needs. Conventions are dynamic, and must adapt as work evolves, as people learn, and as emerging work processes form, as the empirical results here show. Even if it were possible to formally capture conventions, it would require a great deal of overhead to continually adapt them. And who would adapt them, the users, or a technical support group? The second argument for conventions is on social grounds. As a face-to-face group develops by merging individual workstyles into a congruent group structure, so should distributed groups, at least to some extent, if they are going to cooperate effectively. The difficulty is that social influences which steer the course of a distributed group are weak. And unfortunately there is currently no more than anecdotal evidence to back up the claim that distributed groups would benefit by having a strong identity, a common language, and cohesive structure. We can only base this claim on the benefits that cohesion brings to physically collocated groups. Conventions can reinforce and strengthen distributed group members' notion of cooperation. This relationship is expressed by the Unit leader who defines conventions as: 
I would use the term obligation, in order to make working together easier. Cooperation is also an important keyword because conventions only make sense in terms of cooperation. ... Conventions only make sense in terms of others.

I would also add that cooperation also only makes sense in terms of conventions. Perhaps this comment, more than any of the other arguments, argues for conventions on the grounds that their existence serves to strengthen social bonds and reinforce the idea for the users that the use of a groupware system is a cooperative group effort.

\section{Conclusion}

In this paper I have presented empirical work which calls attention to the problems that cooperating partners face in handling shared objects in electronic work. Conventions are necessary to help a group keep track of processes, for new members to smoothly adapt, and to help members understand intergroup perspectives and processes. Yet although beneficial, the group in this case study failed to sufficiently form conventions needed for their electronic work. And even the agreements on conventions that the group formed were violated, inconsistent with normative behavior. These difficulties underscore the long road ahead for designers and practitioners of groupware.

Following norms and conventions has been considered to be rational behavior (e.g. Axelrod, 1984). The violations of the conventions in the PoliTeam case however, while superficially may seem irrational, may have been motivated by other factors, such as self-interest in following individual work processes. In other words, what may seem irrational in following conventions for the group may have been fully rational behavior at the individual level. The lesson we may have learned is that a distributed group needs to achieve a level of social development so that people think in terms of what is rational behavior for the group.

With the PoliTeam users, once the system was introduced, the different subgroups of users did not have much opportunity to discuss and merge their different perspectives, and corresponding different procedures. Rather than developing common conventions, the distributed users retained individual (or subgroup) methods, at least for one and one half years. Perhaps one of the most important underlying reasons why the group required so long to develop conventions, and why there was difficulty in sustaining them, was the constrained social accommodation to the group, which according to Moreland and Levine (1989) lead to commitments to the group.

Through their regular and ongoing interaction, a physically collocated group has the opportunity to merge different perspectives among members and develop a cohesive set of ideas on its identity, culture, rituals, procedures, etc. In the process of a group forming, actors slowly merge their individual attitudes and develop a new set of "group" attitudes, identifications, and behaviors, which becomes a 
collective, or congruent structure (Weick, 1969; Newcomb, 1968). Schein (1985) further describes this process:

Goals, means, working procedures, measurements, and rules of interaction all have to be forged out of common experience, and a sense of mission, what the group is ultimately all about, develops only as members begin genuinely to understand each other's needs, goals, talents, and values and begin to integrate these into a shared mission. (p. 188)

Commitments to the group, and to its procedures, are developed as part of this overall accommodation process (Moreland and Levine, 1989). During this group development process, conventions evolve in a suitable way for the group. In faceto-face interaction, many conventions are formed early on in a group's history and remain (Schein, 1985), such as seeing the order of turn-taking. This case study illustrated that the formation of such implicit conventions is difficult to achieve in a group who seldom meets face-to-face.

The experience of the PoliTeam users is probably typical for many groups cooperating in electronic work. The typists and unit members had cooperated prior to the system introduction with one another, but there were far less interdependencies in their paper-based transactions than in their electronic work, and certainly of a different nature. Because they worked in different areas of the ministry, the two subgroups had minimal contact (document exchange was primarily via courier). As in the case of many groupware introductions, the two groups stemming from different departments began a new cooperation, but did not have the opportunity to merge into what Schein (1985) describes as a cohesive group, through a social accommodation process.

In this paper, I have tried to provide empirical ground for the use of awareness in electronic cooperation. As a result, I propose that awareness takes on a new function, namely to help cooperating partners learn about each others' activities as an aid in identifying coordination situations, and as a means of feedback to shape normative convention behavior. A feedback channel can serve to reinforce and shape desirable behaviors and correct undesirable behaviors in the group. Above all, it may serve to clarify for actors that they are cooperating in a system where their actions are interdependent. Awareness can aid group members in making local decisions on how to proceed with their work, and when accumulated, can aid articulation through increasing mutual knowledge, and consequently expectations of others' behaviors.

Since I propose awareness as a learning device, this type of awareness information may be turned off when users have achieved their goal of identifying models of usage, and of learning actions and effects. In this way it can address an information overflow problem. But it is important to emphasize that such learning takes time. Habits must first settle into place: people must learn which functionality will be used, and how. A caveat is that while such awareness information brings benefits, it will also impose overhead on users. But this information overhead must be countered by the process loss that will be prevented if group members successfully 
learn to follow conventions. There is far more to be understood about designing support for distributed groups, and the biggest challenges still lie ahead.

\section{Acknowledgments}

I would like to give many thanks to Paul Dourish, Tom Gross, Jonathan Grudin, Thomas Herrmann, Kjeld Schmidt, and Carla Simone for their valuable comments. I also thank Wolfgang Prinz, Konrad Klöckner, Uta Pankoke-Babatz, the rest of the PoliTeam design team members, and especially the users.

\section{Note}

1. Ackerman uses the term "norm", which is similar in meaning to my use of the word conventions.

\section{References}

Ackerman, M.S., D. Hindus, S.D. Mainwaring and B. Starr (1997): Hanging on the 'Wire': A Field Study of an Audio-Only Media Space. ACM Transactions on Computer-Human Interaction, vol. 4, no. 1, pp. 39-66.

Asch, S.E. (1956): Studies of Independence and Conformity: A Minority of One Against a Unanimous Majority. Psychological Monographs, vol. 70, no. 9 (Whole No. 416).

Ashworth, T. (1980): Trench Warfare, 1914-1918: The Live and Let Live System. New York: Holmes \& Meier.

Axelrod, R. (1984): The Evolution of Cooperation. New York: Basic Books.

Baecker, R., D. Nastos, I. Posner and K. Mawby (1993): The User-Centred Iterative Design of Collaborative Writing Software. Proceedings INTERCHI'93. Amsterdam, pp. 399-405.

Bakeman, R. and J.M. Gottman (1986): Observing Interaction: An Introduction to Sequential Analysis. Cambridge: Cambridge University Press.

Ballay, J.M. (1994): Designing Workscape: An Interdisciplinary Experience. In B. Adelson, S. Dumais and J. Olson (eds.): Proceedings of CHI'94 Conference on Human Factors in Computing Systems. ACM Press, pp. 10-15.

Bandura, A. (1971): Social Learning Theory. New York: General Learning Press.

Beck, E.E. and W. Bellotti (1993): Informed Opportunism as Strategy: Supporting Coordination in Distributed Collaborative Writing. Proceedings of ECSCW'93, September 13-17, Milan. Dordrecht: Kluwer Academic Publishers, pp. 233-248.

Bentley, R. and P. Dourish (1995): Medium versus Mechanism: Supporting Collaboration Through Customization. In H. Marmolin, Y. Sundblad and K. Schmidt (eds.): Proc. of Fourth European Conference on Computer Supported Cooperative Work (ECSCW '95). Stockholm, Sweden: Kluwer, pp. 133-148.

Bordetsky, A. and G. Mark (2000): Memory-Based Feedback Controls to Support Groupware Coordination. Information Systems Research, vol. 11, no. 4.

Carroll, J.M. and J.C. Thomas (1982): Metaphors and the Cognitive Representation of Computing Systems. IEEE Transactions on Systems, Man, and Cybernetics, vol. SMC-12, no. 2.

Clark, H.H. (1985): Language use and Language Users. In G. Lindzey and E. Aronson (eds.): Handbook of Social Psychology. New York: Random House.

Conte, R. and C. Castelfranchi (1995): Cognitive and Social Action. London: UCL Press. 
Dourish, P., J. Lamping and T. Rodden (1999): Building Bridges: Customisation and Mutual Intelligibility in Shared Category Management. Proceedings of the ACM Conference on Supporting Group Work (Group' 99).

Dourish and V. Bellotti (1992): Awareness and Coordination in Shared Workspaces. Proceedings of CSCW'92, Oct. 31-Nov. 4, Toronto, pp. 107-114.

Feldman, D.C. (1984): The Development and Enforcement of Group Norms. Academy of Management Review, vol. 9, no. 1, pp. 47-53.

Festinger, L. (1959): Informal Social Communication. Psychological Review, vol. 57, pp. 271-282.

Finnemore, M. and K. Sikkink (1998): International Norm Dynamics and Political Change. International Organization (Autumn), vol. 53, no. 4, pp. 887-917.

Frey, S. (1975): Tonic Aspects of Behavior in Interaction. Organization of Behavior in Face-to-Face Interaction. The Hague: Mouton Publishers, pp. 127-150.

Fuchs, L. (1999): AREA: A Cross-Application Notification Service for Groupware. To appear in Proceedings of ECSCW'99, Copenhagen, Denmark, 12-16 September. Dordrecht: Kluwer Academic Publishers, pp. 61-80.

Gaver, W., R. Smith and T. O'Shea (1991): Effective Sounds in Complex Systems: The ARKola Simulation. Proceedings CHI'91. New Orleans, pp. 85-90.

Gerson, E.M. and S.L. Star (1986): Analyzing Due Process in the Workplace. ACM Transactions on Office Information Systems (July), vol. 4, no. 3, pp. 257-270.

Grinter (1996): Supporting Articulation Working Using Software Configuration Management Systems. CSCW Journal, vol. 5, no. 4, pp. 447-465.

Grudin, J. (1988): Why CSCW Applications Fail: Problems in the Design and Evaluation of Organizational Interfaces. Proceedings CSCW'88, September 26-29. Portland, pp. 85-93.

Gutwin, C. and S. Greenberg (1998): Design for Individuals, Design for Groups: Tradeoffs between Power and Workspace Awareness. Proceedings of CSCW'98, Nov. 14-18. Seattle, pp. 207-216.

Hackman, J.R. (1976): Group Influences on Individuals. In M.D. Dunnette (ed.): Handbook of Industrial and Organizational Psychology. Chicago: Rand McNally.

Hall E.T. (1966): The Hidden Dimension. Anchor Books. New York.

Harper, R.H.R. and J.A. Hughes (1993): What a F-ing System! Send 'em All to the Same Place and Then Expect Us to Stop 'em Hitting. Managing Technology Work in Air Traffic Control. In G. Button (ed.): Technology in Working Order, Studies of Work, Interaction, and Technology. London and New York: Routledge, pp. 127-144.

Heath, C.C. and P. Luff (1992): Collaboration and Control: Crisis Management and Multimedia Technology in London Underground Line Control Rooms. CSCW Journal, vol. 1, nos. 1-2, pp. 69-94.

Heath, C., M. Jirotka, P. Luff and J. Hindmarsh (1993): Unpacking Collaboration: The Interactional Organization of Trading in a City Dealing Room. Proceedings of ECSCW'93, Sept. 13-17, Milan. Dordrecht: Kluwer Academic Publishers, pp. 155-170.

Herrmann, T. and A. Misch (1999): Anforderungen an lehrunterstützende Kooperationssysteme aus kommunikationstheoretishcher Sicht. In A. Schwill, (ed.): Informatik und Schule - Fachspezifische und fachübergreifende didaktische Konzepte, Tagungsband zur 8. GI-Fachtagung: Springer-Verlag.

Hewitt, C. (1985): The Challenge of Open Systems. BYTE (April), vol. 10, no. 4, pp. 223-242.

Hoschka, P., B. Butscher and N. Streitz (1993): Telecooperation and Telepresence: Technical Challenges of a Government Distributed between Bonn and Berlin. Informatization and the Public Sector, vol. 2, no. 4, pp. 269-299.

Hughes, J.A., D. Randall and D. Shapiro (1992): Faltering from Ethnography to Design. Proceedings CSCW'92, Oct. 31-Nov. 4. Toronto: ACM Press, pp. 115-122.

Klöckner, K., P. Mambrey, M. Sohlenkamp, W. Prinz, L. Fuchs, S. Kolvenbach, U. Pankoke-Babatz and A. Syri (1995): PoliTeam: Bridging the Gap between Bonn and Berlin for and with the Users. Proc. of ECSCW'95. Stockholm: Kluwer, pp. 17-32. 
Lenke, N., H.D. Lutz and M. Sprenger (1995): Grundlagen Sprachlicher Kommunikation. Munich: Wilhelm Fink.

Levine, J.M. (1989): Reaction to Opinion Deviance in Small Groups. In P. Paulus (ed.): Psychology of Group Influence. Hillsdale, NJ: Lawrence Erlbaum, pp. 187-232.

Lewis, D.K. (1969): Convention: A Philosophical Study. Cambridge, MA: Harvard University Press.

Malone, T. and K. Crowston (1994): The Interdisciplinary Study of Coordination. ACM Computing Surveys, vol. 6, no. 1, pp. 87-119.

Mambrey, P., G. Mark and U. Pankoke-Babatz (1998): User Advocacy in Participatory Design: Designers Experiences with a New Communication Channel. Computer Supported Cooperative Work (CSCW), an International Journal, vol. 7, pp. 291-313.

Mark, G. and P. Mambrey (1997): Models and Metaphors in Groupware: Towards a Group-Centered Design. In S. Howard, J. Hammond and G. Lindgaard (eds.): Human-Computer Interaction INTERACT'97 (IFIP TC13 Int'l. Conference on Human-Computer Interaction, July 14-18, Sydney). London: Chapman \& Hall, pp. 477-484.

Moreland, R.L. and J.M. Levine (1989): Newcomers and Oldtimers in Small Groups. In P. Paulus (ed.): Psychology of Group Influence. Hillsdale, NJ: Lawrence Erlbaum, pp. 143-186.

Newcomb, T.M. (1968): Interpersonal Balance. In R.P. Abelson (ed.): Theory of Cognitive Consistency - A Sourcebook. Chicago: McNally, pp. 10-51.

Orlikowski, W.J. (1996): Improvising Organizational Transformation over Time: A Situated Change Perspective. Information Systems Research (March), vol. 7, no. 1, pp. 63-92.

Orlikowski, W.J. and D.C. Gash (1994): Technological Frames: Making Sense of Information Technology in Organizations. ACM Transactions on Information Systems, vol. 12, no. 2, pp. 174-207.

Prinz, W., G. Mark and Pankoke-Babatz (1998): Designing Groupware for Congruency in Use. Proceedings of the ACM 1998 Conference on Computer Supported Cooperative Work (CSCW'98). New York: ACM Press, pp. 373-382.

Prinz, W. and S. Kolvenbach (1996): Support for Ministerial Workflows. In M.S. Ackermann (ed.): Proc. of Conference on Computer Supported Cooperative Work (CSCW'96). Boston, MA: ACM Press, pp. 199-208.

Robinson, M. (1993): Design for Unanticipated Use. Proceedings of ECSCW'93, Sept. 13-17, Milan. Dordrecht: Kluwer Academic Publishers, pp. 187-202.

Robinson, M. (1991): Double-Level Languages and Co-Operative Working. AI and Society, vol. 5, pp. 34-60.

Rogers, Yvonne (1993): Coordinating Computer-Mediated Work. Computer Supported Cooperative Work (CSCW), an International Journal, vol. 1, pp. 295-315.

Schein, E.H. (1985): Organizational Culture and Leadership. San Francisco: Jossey-Bass.

Schmidt, K. and C. Simone (1996): Coordination Mechanisms: Towards a Conceptual Foundation of CSCW System Design. CSCW: The Journal of Collaborative Computing, vol. 5, nos. 2-3, pp. 155-200.

Schmidt, K. and L. Bannon (1992): Taking CSCW Seriously: Supporting Articulation Work. Computer Supported Cooperative Work (CSCW), an International Journal, vol. 1, nos. 1-2, pp. 7-40.

Schutz, A. (1970): On Phenomenology and Social Relations. Chicago: The University of Chicago Press.

Simone, C., G. Mark and D. Giubbilei (1999): In D. Georgakopoulos, W. Prinz and A. Wolf (eds.): Proceedings of ACM Conference on Work Activities Coordination and Collaboration (WACC'99), Feb. 22-25. San Francisco: ACM Press, pp. 39-48.

Smith, E.E. and S.S. Kight (1959): Effects of Feedback on Insight and Problem-Solving Efficiency in Training Groups. Journal of Applied Psychology, vol. 43, pp. 209-211. 
Sohlenkamp, M., L. Fuchs and A. Genau (1997): Awareness and Cooperative Work: The PoliTeam Approach. Proceedings of HICSS 30, Jan. 9-11, Wailea. Hawaii: IEEE Computer Society Press, pp. 549-558.

Star, S.L. and J.R. Griesemer (1989): Institutional Ecology, 'Translations' and Boundary Objects: Amateurs and Professionals in Berkeley's Museum of Vertebrate Zoology, 1907-1939. Social Studies of Science, vol. 19, pp. 387-420.

Stefik, M., G. Foster, D. Bobrow, K. Kahn, S. Lanning and L. Suchman (1987): Beyond the Chalkboard: Computer Support for Collaboration and Problem Solving in Meetings. Communications of the ACM, vol. 30, no. 1, pp. 32-47.

Syri, A. (1997): Tailoring Cooperation Support Through Mediators. In J. Hughes et al. (eds.): Proceedings of the Fifth European Conference on Computer Supported Cooperative Work (ECSCW'97). pp. 157-172.

Tajfel, H. (1969): Social and Cultural Factors in Perception. In G. Lindzey and E. Aronson (eds.): Handbook of Social Psychology. Reading, MA: Addison-Wesley.

Tatar, D., G. Foster and D. Bobrow (1991): Design for Conversation: Lessons from Cognoter. IJMMS. vol. 34, no. 2, pp. 185-209.

Turner, J.C. and Oakes (1989): Self-Categorization Theory and Social Influence. In P.B. Paulus (ed.): Psychology of Group Influence. Hillsdale, NJ: Lawrence Erlbaum Associates, pp. 233-275.

Waldenfels, B. (1994): Der Stachel des Fremden. Frankfurt: Suhrkamp.

Waltz, K.N. (1979): Theory of International Politics. Reading, MA: Addison-Wesley.

Weick, K.E. (1969): The Social Psychology of Organizing. Reading, MA: Addison-Wesley.

Wulf, V. (1997): Storing and Retrieving Documents in a Shared Workspace: Experiences from the Political Administration. In S. Howard, J. Hammond and G. Lindgaard (eds.): Human Computer Interaction: INTERACT'97. UK: Chapman \& Hall. 
